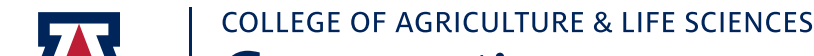 Cooperative Extension
}

\section{Sustainability of the Beef Industry}

\author{
Dan B. Faulkner
}

Retailers of beef products are increasingly requesting producers to document practices related to sustainability. Sustainability was a feel good term with many definitions until it was recently defined. The multi stakeholder (including input from NCBA) Global Roundtable for Sustainable Beef (GRSB) recently defined sustainable beef as "a socially responsible, environmentally sound and economically viable product that prioritizes: the planet (relevant principles include natural resources, efficiency and innovation, people and the community), people (principles include people, the community and food), animals (principles include animal health and welfare, efficiency and innovation) and progress (principles include natural resources, people and the community, animal health and welfare, food, efficiency and innovation)". This definition is broad but it at least provides a framework for us to discuss the issue of sustainability.

The National Beef Quality Audits, Cattlefax, NAMS and other sources provide some valuable information regarding improved sustainability for the beef industry. In the 22 years since the first National Beef Quality Audit in 1991 the beef industry has decreased overall losses in the industry by $58 \%$ ( $\$ 12$ billion). If we look at the industry changes that reduced these losses in more detail, we find improvements in some areas and little change in others.

\section{Reproduction}

If we look at reproduction, there has been no change according to NAMS data. We still average about $80 \%$ nationally. Many models suggest that about $90 \%$ would be optimal for the industry if we balance inputs costs with reproductive performance. If we take care of health issues, the varied nutritional environments for cows across the US will still limit reproduction in certain areas.

\section{Death Loss}

Death loss has not changed in the past 22 years based on Cattlefax data and feedlot closeout data published by Feedstuffs. We still average about $4.2 \%$ at or near birth and
2.3\% from birth to slaughter. Improved health and weaning programs and the use of bulls with a good calving ease EPD could reduce industry death losses.

\section{Weaning Weight}

According to cattlefax, we have dramatically increased weaning weight by over 100 pounds. It has been estimated that this improvement is about $70 \%$ genetics and $30 \%$ management. We are also feeding cattle to heavier market weights because weight is the primary driver of income and genetics have changed to allow us to feed cattle to heavier weights without getting them excessively fat. This has resulted in more outliers due to weight. Heavy weight carcasses increased from 6.9 to $11.1 \%$ despite industry maximum carcass weight changes from 900 to $1050 \mathrm{lbs}$. Despite the increase in outliers due to weight, the overall incidence of outliers decreased in response to increased grid purchases which sent market signals. The desire to feed cattle to heavier weights has resulted in little change in overall fat thickness.

\section{Preconditioning}

More cattle are being processed in response to increased value for preconditioned calves. For example, only $6 \%$ of calves marketed through Superior Livestock last year were not vaccinated prior to sale. Why these improved health programs have not resulted in reduced death losses for the industry is not clear. It could be related to not weaning the calves and teaching then to eat from a bunk prior to sale. The increase in vaccination programs has resulted in more multiple processing which has increased costs for the industry (\$110 million). Many feedlot producers still vaccinate all calves coming into the feedlot, because they are not comfortable with the vaccination programs prior to entering the feedlot. Another problem is that many cattle are comingled prior to entering the feedlot. These cattle may come from various vaccination programs or no vaccination program and have little or no documentation of their program. The reduction in injection site lesions from about $22 \%$ to less than $3 \%$ is an 
industry success story. This is due to more subcutaneous injections and injecting in the neck instead of the rump. This is based on Cattlefax data and data from the National Beef Quality Audit.

\section{Feed Intake and Efficiency}

Feed efficiency has dramatically improved from 7:1 to 5.75:1 (feed to gain) resulting in $\$ 75$ million in savings to the industry. This is related to feeding more calves (which are more efficient) instead of yearlings. The improvement in rate of gain has also improved feed efficiency. Improving gain has more impact on efficiency than changes in feed intake. Changes in intake could improve cow efficiency, reproductive performance and have some impact on feed efficiency by reducing inputs. This is documented in Cattlefax data and feedlot closeout data published by Feedstuffs. Simple calculations show that if we would simply eliminate the bottom $5 \%$ of calves that have poor health and/or poor genetics, we could dramatically improve returns for the entire industry. For example, if we eliminate the calves in a feedlot pen that gain less than 2.5 pounds per day, we double the pen profit.The National Beef Quality Audit found that there has been no change in hot iron branding. About $45 \%$ of beef cattle are branded nationally at a cost to the industry of $\$ 18$ million. There is no market signal to decrease hot iron branding and it is needed for identification in many areas with range cattle. We have seen some changes in location of brands. There is more hip branding and rib branding has decreased from 13.8 to $9 \%$. Hides with hip brands have more value than hides with rib brands.

\section{Summary}

We have done a good job of improving the sustainability of the beef industry over the past 22 years, but there are still changes we can make to further improve it. Many of these changes have a direct economic benefit to beef producers. I would encourage you to look at the identified areas that need improvement and make changes to benefit you and the beef industry.

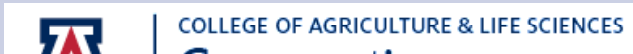 Cooperative Extension}

The University of ARizona College of Agriculture and Life Sciences Tucson, ARIZONa 85721

DAN B. FAULKNeR

Beef Specialist

CONTACT :

DAN B. FAULKNer

dfaulkner@email.arizona.edu

This information has been reviewed by University faculty. extension.arizona.edu/pubs/az1695-2016.pdf

Other titles from Arizona Cooperative Extension can be found at: extension.arizona.edu/pubs

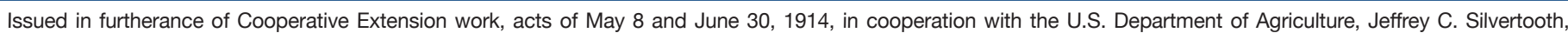
Associate Dean \& Director, Extension \& Economic Development, College of Agriculture Life Sciences, The University of Arizona.

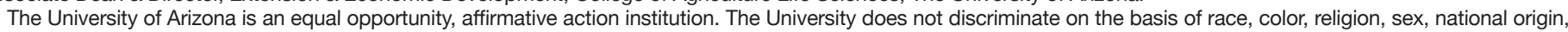
age, disability, veteran status, or sexual orientation in its programs and activities. 